\title{
Hypermnesia: The role of multiple retrieval cues
}

\author{
HAJIME OTANI \\ Central Michigan University, Mount Pleasant, Michigan \\ ROBERT L. WIDNER, JR. \\ University of Colorado, Colorado Springs, Colorado \\ and University of Colorado, Boulder, Colorado \\ and \\ HOWARD L. WHITEMAN and J. PAUL ST. LOUIS \\ Central Michigan University, Mount Pleasant, Michigan
}

\begin{abstract}
We demonstrate that encoding multiple cues enhances hypermnesia. College students were presented with 36 (Experiment 1) or 60 (Experiments 2 and 3) sets of words and were asked to encode the sets under single- or multiple-cue conditions. In the single-cue conditions, each set consisted of a cue and a target. In the multiple-cue conditions, each set consisted of three cues and a target. Following the presentation of the word sets, the participants received either three cued recall tests (Experiments 1 and 2) or three free recall tests (Experiment 3). With this manipulation, we observed greater hypermnesia in the multiple-cue conditions than in the single-cue conditions. Furthermore, the greater hypermnesic recall resulted from increased reminiscence rather than reduced intertest forgetting. The present findings support the hypothesis that the availability of multiple retrieval cues plays an important role in hypermnesia.
\end{abstract}

Research has shown that memory performance improves over repeated tests even though participants are not reexposed to the material between tests. This improvement, referred to as hypermnesia, is the result of two converse processes: reminiscence and intertest forgetting (Brown, 1923). Reminiscence occurs when a previously unrecalled item is recalled on a subsequent test, whereas intertest forgetting occurs when a previously recalled item is not recalled on a subsequent test. When reminiscence exceeds forgetting, there is a net increase in memory performance across test trials. Ballard (1913) was the first to demonstrate this phenomenon, but the modern investigation of hypermnesia was initiated by Erdelyi and Becker (1974). Subsequently, numerous studies have been directed at identifying the basic mechanisms that are responsible for hypermnesia (see Erdelyi, 1996, and Payne, 1987, for extensive reviews). These studies have shown that hypermnesia occurs with a variety of materials, including pictures (e.g., Yarmey, 1976) as well as words (e.g., Roediger, Payne, Gillespie, \& Lean, 1982).

Experiments 1 and 2 were conducted in partial fulfillment of the requirements of the MA degree at Central Michigan University by the third and fourth authors, respectively, under the direction of the first author. The authors thank Terry Libkuman, Renee Babcock, Josh Landau, Daniel Burns, and Robert Greene for helpful comments on the manuscript. Correspondence should be addressed to H. Otani, Department of Psychology, Central Michigan University, Mount Pleasant, Ml, 48859 (e-mail: hajime.otani@cmich.edu).
According to Roediger and his colleagues (e.g., Payne, Hembrooke, \& Anasatasi, 1993; Roediger \& Challis, 1989; Roediger \& Thorpe, 1978), hypermnesia is based on two processes, both of which are incorporated into the search of associative memory (SAM) model proposed by Raaijmakers and Shiffrin $(1980,1981)$. The first is the process of incrementing, in which, once recalled, an item becomes easier to access because recalling an item increases its trace strength as well as the strengths of associations among items, retrieval cues, and the other retrieved items. Consequently, retrieval becomes progressively more efficient as an item is repeatedly recalled on subsequent tests. Roediger and his colleagues assume that this process minimizes intertest forgetting while allowing additional time to search for additional items. The second process is the process of finding alternative retrieval routes. By changing the retrieval cues in short-term memory, one may gain access to previously unretrieved items. As noted by Payne et al. (1993) and Roediger and Challis (1989), such a process is similar in nature to the stimulus sampling hypothesis proposed by Estes (1955. 1959).

The process of incrementing has received substantial support (e.g., Roediger \& Payne, 1982) from findings that recall speed increases across tests. However, to date, no direct test has been conducted on the second process. The purpose of the present series of experiments, therefore, was to test the hypothesis that the availability of alternative retrieval routes contributes to hypermnesia by facilitating the recovery of unretrieved items. Our strategy 
was to manipulate the number of cues that participants encode. We hypothesized that encoding multiple cues would enhance hypermnesia by providing alternate retrieval routes during tests. We used cued (Experiments 1 and 2 ) as well as free (Experiment 3 ) recall to test this hypothesis, because studies have shown that hypermnesia occurs with both (e.g., Payne et al., 1993; Otani \& Hodge, 1991).

\section{EXPERIMENT 1}

In Experiment 1, participants were instructed to encode either one or three cues for each target. In the multiplecue given condition, three cues were provided by the experimenter. In the multiple-cue generate condition, participants were presented with one cue for each target and were asked to generate two additional cues. In the single-cue given condition, participants processed one experimenter-provided cue for each target. In all three conditions, the participants' memory was tested with cued recall in which a single experimenter-provided cue was presented for each target. We hypothesized that hypermnesia would be greater in the multiple-cue conditions than in the single-cue condition because encoded multiple cues would provide alternative retrieval routes during tests. Furthermore, hypermnesia should be greater in the multiple-cue generate than in the multiple-cue given condition because self-generated cues should be more effective than the experimenter-provided cues (e.g., Mäntylä, 1986; Nairne \& Widner, 1988; Widner, 1995). In addition, two types of list, categorized and uncategorized, were used in this experiment because Otani and colleagues (e.g., Otani \& Hodge, 1991; Otani \& Whiteman, 1994) have shown that hypermnesia in cued recall is greater with a categorized list than with an uncategorized list. We therefore thought that multiple cues would interact with the type of list.

\section{Method}

Participants. One hundred thirty-two male and female undergraduate students enrolled in introductory psychology courses at Central Michigan University participated for course credit. A blockrandomization procedure was used to assign an equal number of participants ( $n=11$ ) to one of 12 between-subjects conditions.

Materials. Each list consisted of 36 sets of words derived from the Marshall and Cofer (1970) association norms. To serve as targets in the categorized list, six nouns were selected from each of 6 taxonomic categories. Two nouns were chosen from each of 18 taxonomic categories to serve as targets in the uncategorized list. Imagery values of these targets were high and equated across the two lists (categorized and uncategorized), ranging from 4.0 to 7.0 in the Toglia and Battig (1978) semantic norms.

Within each list type, a single word was chosen to serve as the predominant cue for each target and was the same for all cue conditions. These cues were low to moderate associates of the target words, ranging in ranks from 2 to 9 in the Marshall and Cofer (1970) association norms. For the multiple-cue given conditions, two additional low to moderate associates (range $=1-5$ ) were chosen such that there were no overlapping cues within a list. The associative strength of these items was also equated across lists.
The predominant cue and target word were centered and typed on $3 \times 5$ in. index cards in lowercase letters, with target items underlined (e.g., wood-beaver). The additional associates for the multiplecue given condition were randomly ordered and typed directly beneath the predominant cue. A random sequencing of the cards was then created, with the restriction that no two target words from the same category followed one another. A second sequence consisted of the reverse of the first sequence. Presentation rates were based on the performance of the slowest participant in each session (see Hodge \& Otani, 1996, for a similar procedure).

For the single-cue given condition, a sheet of paper with the numbers 1-36, in three columns, was created, with each number followed by a blank space. For the multiple-cue given and generate conditions, a similar sheet was constructed, but with three blank spaces rather than one for each number. A page of randomly generated two-digit numbers was used for a filler task. Three cued recall tests for each list type were created by arranging the predominant cues in three random sequences. Thus, only one cue was presented for each target in the cued recall tests. Furthermore, the cues used in the cued recall tests were the same for all three conditions.

Procedure. The participants, tested individually or in small groups of 2-6, were instructed to remember the target words for a later and unspecified memory test. To ensure that the participants in all conditions paid attention to the cues and targets, they were instructed to read the items silently as the experimenter read them aloud. During presentation of the list items, the participants in the single-cue given condition were instructed to copy the predominant cue words on a response sheet. In the multiple-cue given condition, the participants were told to copy all three cue words. In the multiplecue generate condition, the participants were instructed to copy the predominant cue and then to generate and write two additional words that would help them remember the target word.

Following processing of the items, the participants performed a filler task for $2 \mathrm{~min}$ in which they were instructed to put a slash through the numbers that were divisible by three and to circle the numbers that were not divisible by three. After the filler task, the participants completed the three cued recall tests, each of which lasted $7 \mathrm{~min}$.

\section{Results and Discussion}

Net recall. The significance level was set at .05 for all analyses unless otherwise specified. The mean correct responses are displayed as a function of cue type and test in Table 1. The list variable was not included in the table because it did not produce any significant effects. Net improvement in performance across the three tests (T3 - T1) was greater in the multiple-cue given and multiple-cue generate conditions than in the single-cue given condition.

A 2 (list) $\times 3$ (cue type) $\times 3$ (test) mixed-design analysis of variance (ANOVA) indicated that the effects of cue type $\left[F(2,126)=14.93, M S_{\mathrm{e}}=109.59\right]$, and test $[F(2,252)=$ $\left.45.45, M S_{\mathrm{e}}=1.30\right]$, and their interaction $[F(4,252)=$ 8.72, $M S_{\mathrm{e}}=1.30$ ], were significant. The main effect of list was not significant $[F(1,126)=2.09]$. Fisher LSD tests showed that overall performance was significantly greater in the multiple-cue generate $(M=26.39, S D=$ $6.77)$ and single-cue given $(M=26.02, S D=5.41)$ conditions than in the multiple-cue given condition $(M=$ $20.11, S D=5.84$ ). No difference was found between the former two conditions. To determine which cue type produced improvement in net recall over three tests, a oneway repeated measures ANOVA was performed on each 
Table 1

Mean Correct Responses, Reminiscence, and Intertest Forgetting as a Function of Cue Type and Test in Experiment 1

\begin{tabular}{|c|c|c|c|c|c|c|}
\hline & \multicolumn{6}{|c|}{ Cue Type } \\
\hline & \multicolumn{2}{|c|}{ SCG } & \multicolumn{2}{|c|}{ MCG } & \multicolumn{2}{|c|}{ MCGen } \\
\hline & $M$ & $S D$ & $M$ & $S D$ & $M$ & $S D$ \\
\hline \multicolumn{7}{|l|}{ Net Recall } \\
\hline Test $1(\mathrm{~T} 1)$ & 25.86 & 6.84 & 19.43 & 5.94 & 25.13 & 5.33 \\
\hline Test 2 (T2) & 25.98 & 6.76 & 20.20 & 5.84 & 26.52 & 5.64 \\
\hline Test 3 (T3) & 26.23 & 6.79 & 20.70 & 5.87 & 27.50 & 5.68 \\
\hline Hypermnesia $(\mathrm{T} 3-\mathrm{T} 1)$ & 0.36 & 1.28 & 1.27 & 1.58 & 2.36 & 2.66 \\
\hline \multicolumn{7}{|l|}{ Reminiscence } \\
\hline Test 2 & 0.73 & 0.82 & 1.32 & 1.03 & 2.07 & 1.63 \\
\hline Test 3 & 0.30 & 0.67 & 0.82 & 0.95 & 1.09 & 1.33 \\
\hline Sum & 1.02 & 1.21 & 2.14 & 1.32 & 3.16 & 2.25 \\
\hline \multicolumn{7}{|l|}{ Intertest Forgetting } \\
\hline Test 2 & 0.61 & 0.81 & 0.55 & 0.73 & 0.70 & 1.10 \\
\hline Test 3 & 0.25 & 0.61 & 0.41 & 0.66 & 0.36 & 0.65 \\
\hline Sum & 0.86 & 1.17 & 0.95 & 1.05 & 1.07 & 1.39 \\
\hline
\end{tabular}

cue condition. The analysis revealed that the difference among the three tests was marginally significant for the single-cue given condition $\left[F(2,86)=2.75, M S_{\mathrm{e}}=0.55\right.$, $p<.07]$. In contrast, there was a significant difference for the multiple-cue given $\left[F(2,86)=18.13, M S_{\mathrm{e}}=1.00\right]$ and generate $\left[F(2,86)=26.18, M S_{\mathrm{e}}=2.37\right]$ conditions. Fisher LSD tests showed that for both multiple-cue conditions, performances on all three tests differed significantly from one another.

To examine the nature of the interaction further, interaction contrasts were performed (cf. Keppel, 1991). The contrasts indicate which condition produced a steeper linear trend over the three tests. The analyses revealed that over the three tests, the multiple-cue generate condition produced a steeper linear trend than did the multiple-cue given condition $\left[F(1,252)=10.08, M S_{\mathrm{e}}=1.30\right]$, which in turn produced a steeper trend than did the single-cue given condition $\left[F(1,252)=7.00, M S_{\mathrm{e}}=1.30\right]$. Hypermnesia, therefore, was greatest for the multiple-cue generate and smallest for the single-cue given condition.

Reminiscence and forgetting. To examine the nature of hypermnesia observed in the multiple-cue given and generate conditions, reminiscence and intertest forgetting were analyzed. Reminiscence was defined in terms of items that were recalled on a given test but were not recalled on a previous test. Intertest forgetting was defined in terms of items that were not recalled on a given test but were recalled on an immediately preceding test. These definitions were adopted from Otani and Whiteman (1994).

Table 1 shows reminiscence and intertest forgetting as a function of cue type and test. As can be seen, reminiscence was greater in the multiple-cue given and generate conditions than in the single-cue given condition. Intertest forgetting, on the other hand, was similar among the three conditions.
A 2 (list) $\times 3$ (cue type) $\times 2$ (test) mixed-design ANOVA on reminiscence revealed that the effects of cue type $\left[F(2,126)=18.40, M S_{\mathrm{e}}=1.37\right]$ and test $[F(1,126)=$ $\left.23.58, M S_{\mathrm{e}}=1.13\right]$ were significant. There was a decrease in reminiscence from Test 2 to Test 3 for all conditions. Fisher LSD tests showed that the multiple-cue generate condition produced greater reminiscence than did the multiple-cue given condition, which in turn produced greater reminiscence than the single-cue given condition. A 2 (list) $\times 3$ (cue type) $\times 2$ (test) mixed-design ANOVA on intertest forgetting revealed that only the effect of test $\left[F(1,126)=10.84, M S_{\mathrm{e}}=0.48\right]$ was significant. In all three cue conditions, intertest forgetting declined from Test 2 to Test 3.

These results indicate that the availability of multiple retrieval cues plays an important role in hypermnesia. Hypermnesia occurred in both the multiple-cue given and multiple-cue generate conditions. In contrast, there was little increase in net recall in the single-cue given condition. The analyses revealed that the greater net improvement in the multiple-cue conditions was based on greater reminiscence rather than on lower intertest forgetting. In addition, contrary to our expectation, the list type did not interact with the number of available cues.

\section{EXPERIMENT 2}

In Experiment 2, we manipulated the number of cues available at both encoding and retrieval. In Experiment 1, we assumed that encoded cues would be used during retrieval to recover items. However, there was no guarantee that participants had used all of the cues at test. By providing participants with multiple cues at retrieval, we expected to increase the likelihood that the cues would be available at retrieval. 
Table 2

Mean Correct Responses, Reminiscence, and Intertest Forgetting as a Function of Cue Type and Test in Experiment 2

\begin{tabular}{|c|c|c|c|c|c|c|}
\hline & \multicolumn{6}{|c|}{ Cue Type } \\
\hline & \multicolumn{2}{|c|}{ Single-Single } & \multicolumn{2}{|c|}{ Multiple-Single } & \multicolumn{2}{|c|}{ Multiple-Multiple } \\
\hline & $M$ & $S D$ & $M$ & $S D$ & $M$ & $S D$ \\
\hline \multicolumn{7}{|l|}{ Net Recall } \\
\hline Test 1 & 25.06 & 10.97 & 12.67 & 5.01 & 30.47 & 12.66 \\
\hline Test 2 & 26.56 & 11.25 & 14.08 & 5.66 & 33.36 & 13.07 \\
\hline Test 3 & 27.75 & 11.47 & 15.11 & 5.70 & 34.39 & 13.31 \\
\hline Hypermnesia (T3 - T1) & 2.69 & 2.61 & 2.44 & 2.55 & 3.92 & 3.22 \\
\hline \multicolumn{7}{|l|}{ Reminiscence } \\
\hline Test 2 & 2.92 & 1.87 & 2.86 & 1.69 & 3.86 & 2.48 \\
\hline Test 3 & 1.31 & 0.98 & 1.55 & 1.34 & 1.53 & 1.08 \\
\hline Sum & 4.22 & 2.18 & 4.42 & 2.09 & 5.39 & 2.96 \\
\hline \multicolumn{7}{|l|}{ Intertest Forgetting } \\
\hline Test 2 & 1.41 & 1.23 & 1.42 & 1.36 & 1.00 & 1.10 \\
\hline Test 3 & 0.89 & 0.99 & 1.11 & 0.94 & 0.92 & 1.05 \\
\hline Sum & 2.31 & 1.75 & 2.52 & 1.70 & 1.92 & 1.79 \\
\hline
\end{tabular}

\section{Method}

Participants. One hundred and eight male and female undergraduate students enrolled in introductory psychology courses at Central Michigan University participated for extra course credit. Block randomization resulted in equal numbers of participants $(n=$ 36) in three between-subjects conditions.

Materials and Procedure. The materials and procedure were the same as those used in Experiment 1, with the following exceptions. First, in the present experiment we used only a categorized list, because the list structure did not produce any effect in Experiment 1 . We increased the number of categories from 6 to 10 , however, because we were concerned about the relatively small net improvement ( $M=1.27$ in the multiple-cue given condition) observed in Experiment 1. The results reported by Otani and St. Louis (1995) suggest that the magnitude of hypermnesic recall increases as more items are included in the list. We, therefore, added six sets of items from each of four new categories. The procedure used to construct additional word sets was the same as that used in Experiment 1 . Second, to examine the availability of cues at retrieval, we had participants in one condition encode multiple cues and provided multiple cues at retrieval (the multiple-multiple condition). For this condition, cued recall tests consisted of a predominant cue plus two additional cues for each target word. In the other two conditions, cued recall consisted of only the predominant cue, whether there was a single cue at encoding (the single-single condition) or multiple cues (the multiple-single condition). Third, the multiple-cue generate condition was eliminated, because it was more difficult to provide self-generated idiosyncratic cues at retrieval.

\section{Results}

Net recall. Table 2 shows the mean correct responses as a function of cue type and test. As can be seen, performance improved over the three tests for all cue conditions. However, the amount of net improvement (T3 T1) was greatest in the multiple-multiple condition. Surprisingly, the amount of improvement in net recall was similar between the single-single and multiple-single conditions.

A 3 (cue type) $\times 3$ (test) mixed-design ANOVA showed that the effects of cue type $[F(2,105)=30.89$,
$\left.M S_{\mathrm{e}}=319.74\right]$ and test $\left[F(2,210)=88.28, M S_{\mathrm{e}}=2.86\right]$ and their interaction $\left[F(4,210)=2.79, M S_{\mathrm{e}}=2.86\right]$ were significant. Fisher LSD tests indicated that the multiplemultiple condition $(M=32.74, S D=12.93)$ produced the greatest performance, followed, in order, by the singlesingle $(M=26.45, S D=11.16)$ and multiple-single $(M=$ $13.95, S D=5.29$ ) conditions. One-way repeated measures ANOVAs performed on each cue condition showed that performance improved over the three tests for all three conditions [single-single, $F(2,70)=26.49, M S_{\mathrm{e}}=$ 2.48; multiple-single, $F(2,70)=19.61, M S_{\mathrm{e}}=2.76$; and multiple-multiple, $\left.F(2,70)=44.45, M S_{\mathrm{e}}=3.34\right]$. The LSD tests showed that performance on all three tests differed significantly for all cue conditions. Next, interaction contrasts were conducted to determine whether or not the cue $X$ test interaction effect was based on a greater increase in memory performance across tests by participants in the multiple-multiple condition as opposed to participants in the other cue conditions. The contrasts showed that the linear trend was significantly steeper for the multiple-multiple,condition than for the single-single condition $\left[F(1,210)=4.70, M S_{\mathrm{e}}=2.86\right]$ or for the multiple-single condition $\left[F(1,210)=6.82, M S_{\mathrm{e}}=2.86\right]$. On the other hand, the linear trend was similar for the singlesingle and multiple-single conditions $[F(1,210)=0.20$, $\left.M S_{\mathrm{e}}=2.86\right]$.

The analysis of net recall performance, therefore, indicated that hypermnesia was similar between the singlesingle and multiple-single conditions. In contrast, hypermnesia was greater in the multiple-multiple condition than in either the single-single or the multiple-single condition. Next, we conducted separate analyses for reminiscence and intertest forgetting.

Reminiscence and intertest forgetting. Table 2 shows the means for reminiscence and intertest forgetting. As can be seen, reminiscence was greater in the multiplemultiple condition than in the single-single or multiple- 
Table 3

Mean Correct Responses, Reminiscence, and Intertest Forgetting as a Function of Cue Type and Test in Experiment 3

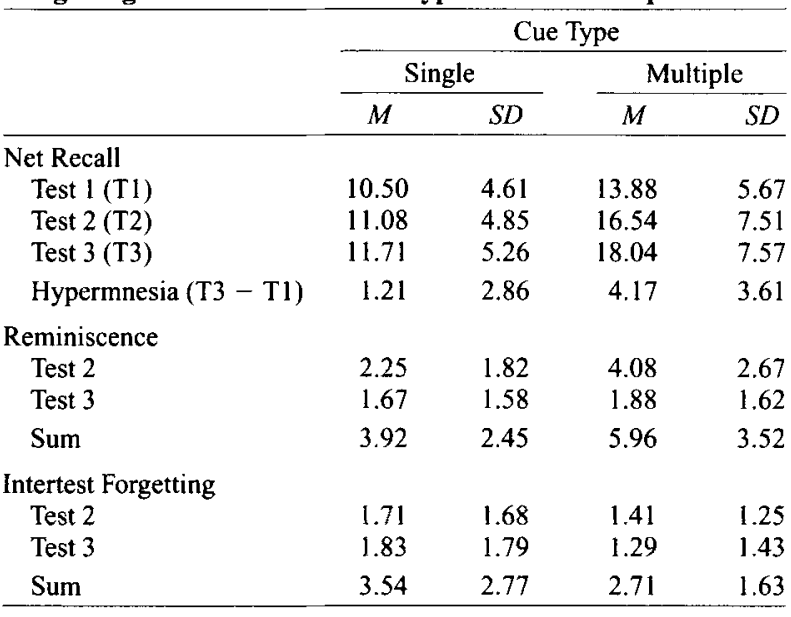

single conditions. Unfortunately, a 3 (cue type) $\times 2$ (test) mixed-design ANOVA of reminiscence indicated that only the effect of test was significant $[F(1,105)=66.00$, $\left.M S_{\mathrm{e}}=2.51\right]$. However, planned comparisons indicated that the multiple-multiple condition produced significantly greater reminiscence than did the single-single condition $\left[F(1,105)=4.10, M S_{\mathrm{e}}=5.98\right]$. No difference was found between the multiple-single and single-single conditions $\left[F(1,105)<1, M S_{\mathrm{e}}=5.98\right]$ or between the multiplemultiple and multiple-single conditions $[F(1,105)=2.85$, $\left.M S_{\mathrm{e}}=5.98\right]$.

A 3 (cue type) $\times 2$ (test) mixed-design ANOVA of intertest forgetting also showed that only the effect of test was significant $\left[F(1,105)=5.16, M S_{\mathrm{e}}=0.98\right]$. Intertest forgetting declined from Test 2 to Test 3 . Planned comparisons indicated that forgetting was similar among the three cued conditions.

The results of Experiment 2 revealed that hypermnesia was greater when multiple cues were available at encoding and test. As in Experiment 1, an increase in reminiscence, rather than a decrease in intertest forgetting, was responsible for the greater hypermnesia observed in the multiple-multiple condition. Surprisingly, the amount of net recall improvement was similar between the singlesingle and multiple-single conditions. Encoding multiple cues, therefore, does not guarantee that participants use the cues during retrieval.

\section{EXPERIMENT 3}

The findings of Experiments 1 and 2 support the hypothesis that the availability of multiple retrieval cues increases hypermnesia. Only cued recall was used in these experiments, however, whereas previously, hypermnesia had been studied primarily with free recall tests (see Payne, 1987). Therefore, in Experiment 3, a free recall task was used to extend the generality of our findings.

\section{Method}

Participants. Forty-eight male and female undergraduate students enrolled in introductory psychology courses at Central Michigan University participated for extra course credit. Equal numbers of participants $(n=24)$ were assigned to two between-subjects conditions, using a block-randomization procedure

Materials and Procedure. The materials and procedure were the same as those in Experiment 2, except that free recall tests, rather than cued recall tests, were administered. The participants received blank sheets of paper and were instructed to write, in any order, as many target words as they could remember. The use of free recall eliminated the necessity of having two separate conditions for the multiple-cue condition (multiple-single and multiple-multiple).

\section{Results and Discussion}

Net recall. Table 3 gives the mean correct responses as a function of cue type and test. As can be seen, the multiplecue condition produced greater improvement across the three tests than did the single-cue condition. A 2 (cue type) $\times 3$ (test) mixed-design ANOVA confirmed that the effects of cue type $\left[F(1,46)=9.02, M S_{\mathrm{e}}=101.96\right]$ and test $\left[F(2,92)=24.22, M S_{\mathrm{e}}=3.63\right]$ and their interaction $\left[F(2,92)=7.63, M S_{\mathrm{e}}=3.63\right]$ were significant. The multiple-cue condition produced significantly greater performance $(M=16.15, S D=6.77)$ than did the singlecue condition $(M=11.10, S D=4.71)$. One-way repeated measures ANOVAs performed on each cue condition revealed that the increase across the three tests was significant for the multiple-cue condition $[F(2,46)=25.06$, $\left.M S_{\mathrm{e}}=4.27\right]$, and marginally significant for the singlecue condition $\left[F(2,46)=2.93, M S_{\mathrm{e}}=3.00, p<.06\right]$. Fisher LSD tests indicated that in the multiple-cue condition all three tests differed significantly from one another. An interaction contrast also indicated that the linear trend was steeper in the multiple-cue than in the single-cue condition $\left[F(1,92)=14.46, M S_{\mathrm{e}}=3.63\right]$.

Reminiscence and intertest forgetting. As Table 3 indicates, reminiscence was greater in the multiple-cue condition than in the single-cue condition. The multiplecue condition also produced less intertest forgetting than did the single-cue condition.

A 2 (cue type) $\times 3$ (test) mixed-design ANOVA of reminiscence confirmed the above observations. The multiple-cue condition produced greater reminiscence than did the single-cue condition $\left[F(1,46)=5.44, M S_{\mathrm{e}}=\right.$ 4.60]. The analysis also indicated that the effect of test $\left[F(1,46)=14.64, M S_{\mathrm{e}}=3.19\right]$ and the cue type $\times$ test interaction $\left[F(1,46)=4.96, M S_{\mathrm{e}}=3.19\right]$ were significant. Fisher LSD tests showed that the difference between the two cue conditions was significant on Test 2 , but not on Test 3 . A 2 (cue type) $\times 3$ (test) mixed-design ANOVA on intertest forgetting did not reveal a significant effect. Intertest forgetting was similar between the two cue conditions.

The findings of Experiment 3 suggest that encoding multiple cues produces greater hypermnesia than does encoding a single cue in free recall. Consistent with the results obtained with cued recall (Experiments 1 and 2), increased reminiscence rather than decreased forgetting 
was responsible for the greater hypermnesia observed in the multiple-cue condition.

\section{GENERAL DISCUSSION}

The results of these three experiments show that the encoding of multiple cues results in increased hypermnesia over that obtained with the use of a single cue. One exception was that the multiple-single condition in Experiment 2 produced net recall improvement similar to that of the single-single condition. It appears that encoding multiple cues does not ensure that participants will take advantage of the extra cues at retrieval. However, when they can take advantage of the multiple cues, as in the multiple-cue generate and multiple-cue given conditions in Experiment 1, the multiple-multiple condition in Experiment 2, and the multiple-cue condition in Experiment 3 , participants do produce greater hypermnesia. The results also indicate that multiple retrieval cues increased hypermnesia by increasing reminiscence rather than decreasing intertest forgetting. This finding is consistent with our expectation that the extra retrieval cues are used to recover previously unretrieved items. Because more than one retrieval cue was available, participants did not have to rely on the same cue to retrieve a target on a different test. However, it was surprising to find that multiple retrieval cues did not reduce intertest forgetting. We thought that because more than one association was formed between cues and targets, multiple cues would reduce the likelihood of a target's being lost. However, in all three experiments, intertest forgetting was similar between the multiple- and single-cue conditions.

These findings are consistent with Roediger and colleagues' (e.g., Payne et al., 1993; Roediger \& Challis, 1989; Roediger \& Thorpe, 1978) proposal that one of the processes involved in hypermnesia is a process of finding alternate retrieval routes, a process incorporated in the SAM model (Raajimakers \& Shiffrin, 1980, 1981). The present results, however, were inconsistent with the cumulative recall level hypothesis. On the basis of the observation that the level of asymptotic recall is often negatively correlated with the rate of approaching asymptote, Roediger and colleagues (e.g., Roediger et al., 1982) proposed that, given two conditions, hypermnesia should be greater in the condition that produces the higher asymptotic level. In Experiment 1, however, the multiple-cue given condition produced hypermnesia, whereas the single-cue given condition did not - even though overall performance was lower in the multiple-cue given condition than in the single-cue given condition. Also, the level of recall was similar between the single-cue given and multiple-cue generate conditions, yet the multiple-cue generate condition resulted in hypermnesia and the singlecue given condition did not.

One puzzling finding was that in Experiment 1, the single-cue given condition produced better performance than did the multiple-cue given condition. This was puzzling, because if multiple retrieval cues helped participants retrieve items by providing alternate retrieval routes, performance should have been greater in the multiplecue given condition than in the single-cue given condition. It is possible that to encode three cues provided by the experimenter for each of 36 target words was difficult for the participants, so that the strength of association between the predominant cues and the targets was much weaker in the multiple-cue given condition than in the single-cue given condition. Consequently, performance was much lower in the multiple-cue given condition than in the single-cue given condition. However, once the predominant cues failed to activate the targets, participants in the multiple-cue given condition could use extra cues to retrieve additional items. As a result, performance improved over three tests in the multiple-cue given condition, whereas performance stayed the same in the singlecue given condition.

An alternative explanation of the present results is provided by Hunt and McDaniel (1993; see also Burns, 1993; Klein, Loftus, Kihlstrom, \& Aseron, 1989; McDaniel, Moore, \& Whiteman, 1998). These authors have proposed that hypermnesia is based on the combined effect of relational and item-specific processing. Relational processing produces hypermnesia by reducing intertest forgetting, whereas item-specific processing creates hypermnesia by increasing reminiscence. On the basis of these notions, it would be possible that the multiple-cue advantage in hypermnesia stems from increased itemspecific processing. Because participants were asked to process three cues for each target, distinctiveness of each target word (i.e., item-specific processing) would have been increased, thereby resulting in greater hypermnesia. The item-specific processing explanation, however, predicts greater intertest forgetting in the multiple-cue than in the single-cue conditions. As mentioned earlier, encoding multiple cues did not affect intertest forgetting. In addition, Hunt and McDaniel (1993) have predicted a specific pattern of improvement across repeated tests. In particular, greater item-specific processing should produce a greater increase in performance between Test 2 and Test 3 than between Test 1 and Test 2, because increased reminiscence cannot produce greater improvement until intertest forgetting reaches asymptote. Such a pattern was not observed in the present experiments. It is possible that the use of cued recall prevented such a pattern from appearing because the presence of explicit cues might have reduced the amount of forgetting. However, the predicted pattern was not observed even when free recall was used in Experiment 3.

In conclusion, the present results indicate that the availability of multiple retrieval cues increases hypermnesia by increasing reminiscence. These results, therefore, indicate that multiple retrieval cues play an important role in the production of hypermnesia. 


\section{REFERENCES}

BALLARD, P. B. (1913). Oblivescence and reminiscence. British Journal of Psychology Monograph Supplements, 1, 1-82.

Brown, W. (1923). To what extent is memory measured by a single recall trial? Journal of Experimental Psychology, 6, 377-382.

BURNS, D. J. (1993). Item gains and losses during hypermnesic recall: Implications for the item-specific-relational information distinction. Journal of Experimental Psychology: Learning. Memory, \& Cognition, 19, 163-173.

ERDELYI, M. H. (1996). The recovery of unconscious memories: Hy permnesia and reminiscence. Chicago: University of Chicago Press.

ERDELYI, M. H., \& BECKER, J. (1974). Hypermnesia for pictures: Incremental memory for pictures but not for words in multiple recall trials. Cognitive Psychology, 6, 159-171.

EsTES, W. K. (1955). Statistical theory of spontaneous recovery and regression. Psychological Review, 62, 145-154.

ESTES, W. K. (1959). The statistical approach to learning theory. In S. Koch (Ed.), Psychology: A study of science (Vol 2, pp. 380-490). New York: McGraw-Hill.

HODGE, M. H., \& OTANI, H. (1996). Beyond category sorting and pleasantness rating: Inducing relational and item-specific processing. Memory \& Cognition, 24, 110-115.

HUNT, R. R., \& MCDANIEL, M. A. (1993). The enigma of organization and distinctiveness. Journal of Memory \& Language, 32, 421-445.

KEPPEL, G. (1991). Design and analysis: A researcher's handbook (3rd ed.). Englewood Cliffs, NJ: Prentice-Hall.

Klein, S. B., Loftus, J., Kifllstrom, J. F., \& Aseron, R. (1989). Effects of item-specific and relational information on hypermnesic recall. Journal of Experimental Psychology: Learning, Memory, \& Cognition, 15, 1192-1197.

MäNTYLÄ, T. (1986). Optimizing cue effectiveness: Recall of 500 and 600 incidentally learned words. Journal of Experimental Psychology: Learning, Memory, \& Cognition, 12, 66-71.

Marshall, G. R., \& Cofer, C. N. (1970). Single-word free association norms for 328 responses from the Connecticut cultural norms for verbal items in categories. In L. Postman \& G. Keppel (Eds.), Norms of word association (pp. 321-360). New York: Academic Press.

McDaniel, M. A., Moore, B. A., \& Whiteman, H. L. (1998). Dynamic changes in hypermnesia across early and late tests: A relational/item-specific account. Journal of Experimental Psychology: Learning, Memory, \& Cognition, 24, 173-185.

NAIRNE, J. S., \& WIDNER, R. L., JR. (1988). Familiarity and lexicality as determinants of the generation effect. Journal of Experimental Psychology: Learning, Memory, \& Cognition, 14, 694-699.

OtANI, H., \& Hodge, M. H. (1991). Does hypermnesia occur in recognition and cued recall? American Journal of Psychology, 104, 101116.

OTANI, H., \& ST. LoUIS, J. P. (1995). A further examination of relational and item-specific processing effects on cued recall hypermnesia. Journal of General Psychology, 122, 355-364.

Otani, H., \& Whiteman, H. (1994). Cued recall hypermnesia is not an artifact of response bias. American Journal of Psychology, 107, 401421.

PAYNe, D. G. (1987). Hypermnesia and reminiscence in recall: A historical and empirical review. Psychological Bulletin, 101, 5-27.

Payne, D. G., Hembrooke, H. A., \& Anasatasi, J. S. (1993). Hypermnesia in free recall and cued recall. Memory \& Cognition, 21, 4862.

RaAiJMAKers, J. G., \& Shiffrin, R. M. (1980). SAM: A theory of probabilistic search of associative memory. In G. H. Bower (Ed.), The psychology of learning and motivation: Advances in research and theory (Vol. 14, pp. 207-262). New York: Academic Press.

RaAijmakers, J. G., \& Shiffrin, R. M. (1981). Search of associative memory. Psychological Review, 88, 93-134.

Roediger, H. L., III, \& Challis, B. H. (1989). Hypermnesia: Improvements in recall with repeated testing. In C. Izawa (Ed.), Current issues in cognitive processes: The Tulane Floweree Symposium on cognition (pp. 175-199). Hillsdale, NJ: Erlbaum.

Roediger, H. L., III., \& Payne, D. G. (1982). Hypermnesia: The role of repeated testing. Journal of Experimental Psychology: Learning, Memory, \& Cognition, 8, 66-72.

Roediger, H. L., III, Payne, D. G., Gillespie, G. L., \& Lean, D. S (1982). Hypermnesia as determined by level of recall. Journal of Verbal Learning \& Verbal Behavior, 21, 635-655.

ROEDIGER, H. L., III, \& THORPE, L. A. (1978). The role of recall time in producing hypermnesia. Memory \& Cognition, 6, 296-305.

Toglia, M. P., \& Battig, W. F. (1978). Handbook of semantic word norms. Hillsdale, NJ: Erlbaum.

WIDNER, R. L., JR. (1995). Associative spread as a mediating variable in the generation effect. Memory, 3, 1-19.

YARMEY, A. D. (1976). Hypermnesia for pictures but not for concrete or abstract words. Bulletin of Psychonomic Society, 8, 115-117.

(Manuscript received March 5, 1998; revision accepted for publication October 2, 1998.) 